\title{
Genetic pleiotropy between age-related macular degeneration and 16 complex diseases and traits
}

Felix Grassmann ${ }^{1 \dagger}$, Christina Kiel ${ }^{1 \dagger}$, Martina E. Zimmermann², Mathias Gorski ${ }^{2}$, Veronika Grassmann ${ }^{3}$, Klaus Stark ${ }^{2}$, International AMD Genomics Consortium (IAMDGC), Iris M. Heid² and Bernhard H. F. Weber ${ }^{\text {** }}$

\begin{abstract}
Background: Age-related macular degeneration (AMD) is a common condition of vision loss with disease development strongly influenced by environmental and genetic factors. Recently, 34 loci were associated with AMD at genome-wide significance. So far, little is known about a genetic overlap between AMD and other complex diseases or disease-relevant traits.

Methods: For each of 60 complex diseases/traits with publicly available genome-wide significant association data, the lead genetic variant per independent locus was extracted and a genetic score was calculated for each disease/ trait as the weighted sum of risk alleles. The association with AMD was estimated based on 16,144 AMD cases and 17,832 controls using logistic regression.

Results: Of the respective disease/trait variance, the 60 genetic scores explained on average $4.8 \%(0.27-20.69 \%)$ and 16 of them were found to be significantly associated with $\mathrm{AMD}$ (Q-values $<0.01, p$ values from $<1.0 \times 10^{-16}$ to $1.9 \times 10^{-3}$ ). Notably, an increased risk for AMD was associated with reduced risk for cardiovascular diseases, increased risk for autoimmune diseases, higher HDL and lower LDL levels in serum, lower bone-mineral density as well as an increased risk for skin cancer. By restricting the analysis to 1824 variants initially used to compute the 60 genetic scores, we identified 28 novel AMD risk variants (Q-values $<0.01$, $p$ values from $1.1 \times 10^{-7}$ to $3.0 \times 10^{-4}$ ), known to be involved in cardiovascular disorders, lipid metabolism, autoimmune diseases, anthropomorphic traits, ocular disorders, and neurological diseases. The latter variants represent 20 novel AMD-associated, pleiotropic loci. Genes in the novel loci reinforce previous findings strongly implicating the complement system in AMD pathogenesis.

Conclusions: We demonstrate a substantial overlap of the genetics of several complex diseases/traits with AMD and provide statistically significant evidence for an additional 20 loci associated with AMD. This highlights the possibility that so far unrelated pathologies may have disease pathways in common.
\end{abstract}

Keywords: Age-related macular degeneration, AMD, Genetic risk scores, GRS, Genetic association studies, Complex traits, Shared genetics

\footnotetext{
* Correspondence: bweb@klinik.uni-regensburg.de

tEqual contributors

${ }^{1}$ Institute of Human Genetics, University of Regensburg, Franz-Josef-Strauss-Allee 11,

93053 Regensburg, Germany

Full list of author information is available at the end of the article
} 


\section{Background}

Age-related macular degeneration (AMD) is the most common cause of vision loss in senior citizens [1-3]. One of the first signs of AMD is the appearance of yellowish drusen between the retinal pigment epithelium (RPE) and Bruch's membrane. Drusen comprise extracellular deposits of proteins and lipids and predispose individuals to develop the degenerative late-stage form of the disease [4]. Late-stage AMD manifests as geographic atrophy (GA) or neovascular (NV) AMD although both late-stage forms can be present in the same or in different eyes of a single individual (mixed GA + NV). GA affects up to $50 \%$ of people with late-stage AMD and is defined as a discrete region of RPE atrophy. NV AMD describes the abnormal growth of leaky blood vessels from the choroid or from within the retina resulting in detachment of the RPE, strong immune cell activation, photoreceptor cell death, and eventually widespread RPE damage. Although vision loss is more rapid in NV AMD, visual acuity can be preserved by anti-angiogenic treatment $[5,6]$.

Over the past decade, genome-wide association studies (GWAS) have identified a number of single nucleotide variants (SNVs) as well as copy number variations in complement and complement-related genes that are involved in AMD risk [7-12]. Recently, the International AMD Genomics Consortium (IAMDGC) [13] identified 52 independent genetic variants at 34 loci across the genome to be associated with late-stage AMD, explaining up to $50 \%$ of the heritability of this disorder.

The genetic risk of an individual to develop a disease can be expressed as a genetic score. One concept to calculate such a score is to count the number of risk-increasing alleles. To account for differences between the effect sizes of genetic variants (i.e. the relative influence of each variant on disease risk), the score can be calculated as the weighted sum of risk increasing alleles using the relative effect size of a variant as weight [14]. Such scores effectively summarize the genetic contribution to diseases or traits and allow evaluation of the genetic risk of other diseases and traits and its correlation with AMD risk.

To evaluate shared genetics between AMD and other complex diseases or disease-relevant traits, we computed genetic scores from published genome-wide significant lead variants for 60 diseases and traits [15-81] and examined their association with AMD using data from a large AMD case-control study including more than 33,000 participants.

\section{Methods}

\section{Description of dataset}

In total, we included data from 16,144 people with latestage AMD (NV, GA, or both, GA/NV AMD) and 17,832 control individuals without AMD, all unrelated and of
European ancestry [13]. Inclusion and exclusion criteria as well as detailed information on ophthalmological grading, quality control of genetic data as well as imputation are given in detail elsewhere [13]. The dataset contained 14,352 men and 19,624 women. Twenty-six studies with different study designs contributed to this dataset, including six population-based studies (2166 cases, 4246 controls).

\section{Diseases and traits under evaluation}

We searched PubMed (www.pubmed.gov) for GWAS of human diseases and traits which included primarily individuals of European descent and publication dates prior to April 2016 (Additional file 1: Figure S1). In addition, we queried GWAS Central (www.gwascentral.org/browser) using the same criteria. GWAS were excluded when no genome-wide significant variants $\left(p<5.00 \times 10^{-8}\right.$ or $\log 10$ $\mathrm{p}<-7.3010)$ were reported or when relevant data such as effect sizes, effect alleles, or $p$ values of association were missing. We also excluded GWAS dealing with diseases and traits mainly attributable to childhood or pregnancy and behavioral/lifestyle traits. In total, we selected $60 \mathrm{hu}$ man diseases or traits that were eligible for further analysis.

\section{Calculation of genetic (risk) scores}

For each of the 60 diseases/traits, we extracted independent genetic variants associated with each of the diseases/traits from the relevant publication, provided their individual association reached genome-wide significance $\left(\mathrm{p}<5.00 \times 10^{-8}\right.$ or $\left.\log 10 \mathrm{p}<-7.3010\right)$ (Additional file 1 : Figure S1 and Additional file 2: Table S1). SNVs were included with an imputation quality $>0.3$, but only those for which we could determine the risk increasing (effect) allele and the associated effect size. Structural variants (e.g. deletions or duplications) were included if they could be imputed reliably (imputation quality $>0.3$ ) into the IAMDGC dataset. Otherwise, if available, proxy variants with $\mathrm{R}^{2}>0.95$ with sufficient imputation quality were chosen. In this analysis, a locus region was defined by a genome-wide significant variant and variants within $\pm 1 \mathrm{Mbp}$. For each locus, only the lead variant (i.e. the variant with the smallest $p$ value for association) was included to represent the relevant disease-/trait-associated haplotype. In a few cases with multiple independent variants reported within a locus, we included all of these. We excluded diseases/traits with less than three genome-wide significant variants published. To account for differences in effect sizes, we extracted the relevant measure of the effect for each of the identified variant (log odds ratio [LOR] for binary outcome, log hazard ratio [HR] for survival, or slope for continuous outcome) from published sources for the respective lead variant (Additional file 2: Table S1).

For each disease/trait, the genetic score was calculated as reported in [14] with slight modifications. Briefly, the 
number of risk increasing alleles, each weighted (multiplied) by the respective effect size (LOR, log HR, or linear regression slope), were counted and the total divided by the average weight. Thus, an individual with a genetic score that is one unit larger than the genetic score of another individual has one additional risk-increasing allele with average effect size. An individual with a genetic score of 50 would have 50 "average" risk-increasing alleles. In addition to the 60 genetic scores for the selected diseases/ traits, we computed the genetic score for AMD based on 52 identified independent AMD variants [13].

The diseases/traits included in the study and the respective publications used to extract the variants and effect sizes are listed in Additional file 2: Table S1. The variants of the traits that were included in the analysis and further information on these variants are listed in Additional file 3: Table S2.

Correlation between genetic scores and variance explained We computed the correlation coefficient between selected genetic scores in $\mathrm{R}$ [82]. The results were plotted with the function heatmap2 from the gplots package [83] using a diverging color palette implemented in the package RColorBrewer [84]. In addition, we estimated the disease/trait variance explained by each variant used to calculate the individual genetic score. In case the disease/trait is dichotomous (e.g. coronary artery disease or psoriasis [PSO]), we extracted the relevant ORs and allele frequencies and calculated the variance explained using a liability threshold model [85]. In case a disease/ trait is continuous (e.g. body mass index, height), we calculated the variance explained directly from the respective linear slopes and standard errors.

\section{Association of the genetic scores with AMD}

To understand the role of the genetic background of each of the 60 diseases/traits for AMD, we conducted association analyses for each of the 60 genetic scores with AMD using logistic regression. Each model was adjusted for DNA source (whole genome amplification: yes/no) and principal components to control for potential subpopulations. Additionally, adjustments were done for age and gender [13].

To account for the multiple association testing of the 60 genetic scores, which were correlated due to shared variants or loci, we controlled the false discovery rate (FDR) to be smaller than 1\% [86].

The strength of association of genetic scores and variants are reported as the log odds ratio (LOR). The OR depicts the AMD risk increase per unit increase in the genetic score that is the AMD risk increase per one additional risk allele with average effect size.

Additional association testing was performed by subgroups, separately for participants at higher age versus lower age (cutoff: age 75 years), for men and women, and by disease subtype (restricting the cases to GA or to $\mathrm{NV} /$ mixed GA + NV using the same controls). For the ocular specific diseases/traits, we additionally restricted the analysis to individuals from population-based studies to avoid possible confounding effects.

\section{Identification of novel AMD-associated variants and loci}

Given the substantial overlap of genetic disease/trait scores with AMD, we reasoned that shared pathways exist and that there might be even more AMD variants among those associated with other diseases/traits. Therefore, we computed the association with AMD for each variant used to compute any of the 60 genetic scores applying logistic regression adjusted for age, gender, DNA source, and the first two principle components. We controlled the FDR to be smaller than $1 \%$. Variants located in one of the 34 known AMD-associated loci [13] were considered to be known variants. To substantiate the independence of the selected variants, we additionally conducted the analyses adjusting for all of the 52 independent AMD-associated variants.

\section{Pathway enrichment analysis based on novel and known AMD risk variants}

To derive information on potential genes influenced by the observed association signal, we extracted all genes of a region around the respective variant. Here, we used the same locus definition as previously reported [13] (most distant variant with $\mathrm{R}^{2}>0.5$ in a region \pm 100 $\mathrm{Kbp})$. In addition, we added the genes from 34 known AMD loci [13]. The resulting gene list was subjected to pathway enrichment analysis using INRICH [87]. We queried significantly enriched KEGG, GO, and Reactome pathways and required at least four genes of the gene list to be present in the respective pathway. The FDR was controlled at $1 \%$.

\section{Annotation of novel associated and linked variants}

We extracted the position of novel associated variants as well as their correlated variants $\left(R^{2}>0.5\right)$ and used the Variant Effect Predictor on www.ensembl.org to find variants in the coding region of a gene [88].

\section{Results}

Selection of variants and computation of genetic scores We extracted 1876 independent genome-wide significant variants for 60 diseases/traits from previously published sources (Additional file 1: Figure S1 and Additional file 2: Table S1). For each disease/trait, we computed a weighted genetic score in our 16,144 cases with latestage AMD (NV AMD, GA, or both NV/GA AMD) and 17,832 controls without signs of early-stage or late-stage AMD. Additionally, we computed a genetic score for AMD based on the 52 identified AMD variants [13]. 


\section{Pairwise correlation of genetic scores}

To understand the dependencies between the genetic scores, pair-wise correlation coefficients of the scores were investigated (Fig. 1). We observed plausible correlations between genetic scores particularly of traits related to autoimmunity (inflammatory bowel disease, Crohn's disease and ulcerative colitis, rheumatoid arthritis (RA), PSO; Spearman correlation coefficient $r$ in the range of 0.01$0.85)$, cardiovascular disease risk, and lipid levels in blood (blood pressure, coronary artery disease, hypertension, high density lipoprotein (HDL), low density lipoprotein (LDL), total cholesterol and total glycerol; $r$ in the range of -0.360.98). Interestingly, the score for the glaucoma-related trait "optic disc/disc area" (ODDA) was not correlated to the genetic score of primary open angle glaucoma (POAG, $r=$ 0.00 ), indicating that both phenotypes share no known genetic overlap. In summary, these correlations are in line with known relationships of the respective diseases and traits $[24,40]$ and with previously published correlations between genetic loci of diseases/traits [89]. On average, the

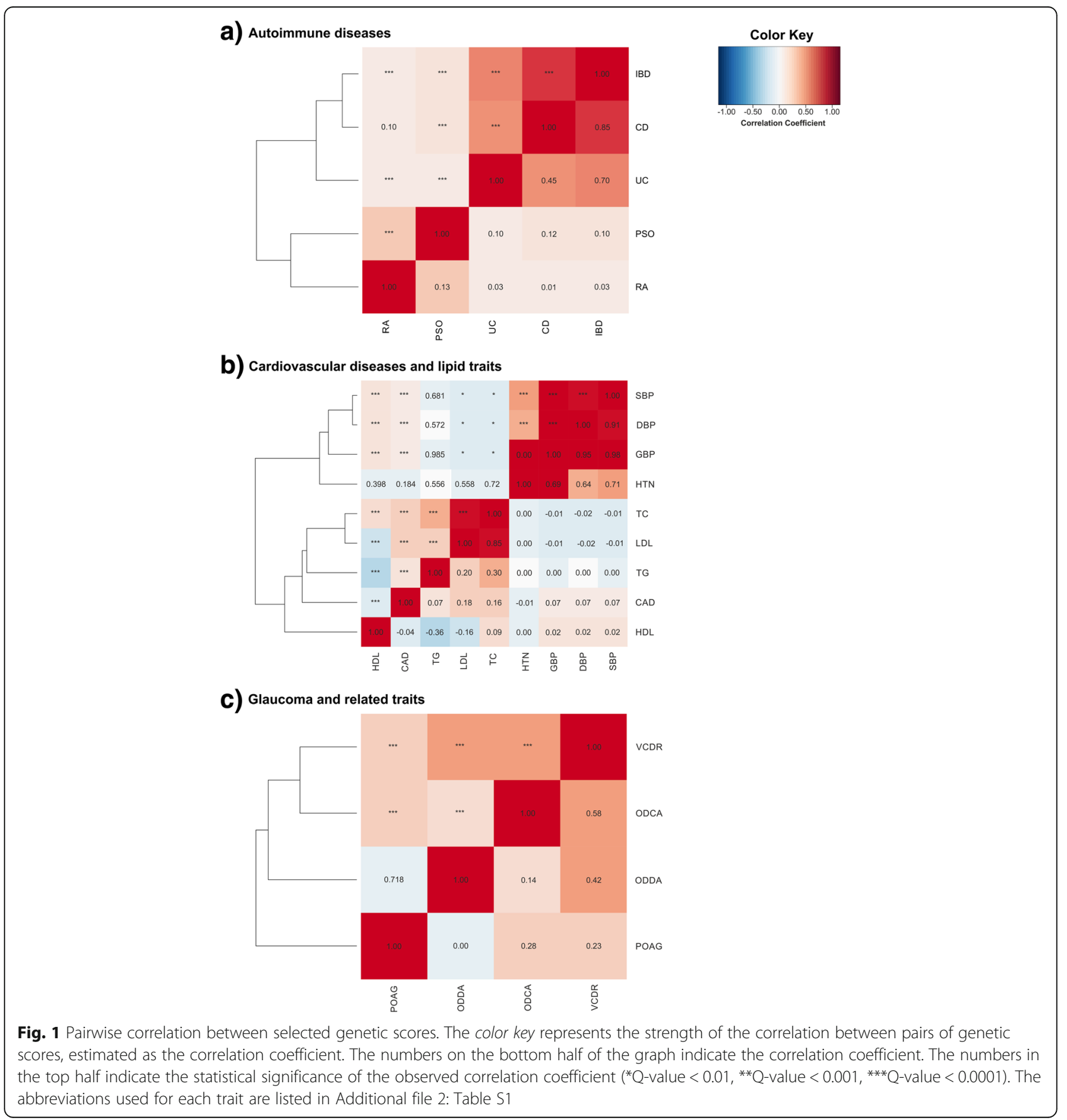


60 genetic scores explain $4.81 \%$ of the variance of each disease/trait.

\section{Association of genetic scores with AMD}

Next, we investigated the association of the 60 calculated genetic scores with AMD using logistic regression models, adjusted for age, gender, DNA source, and the first two principle components. We found a statistically significant association for the genetic scores for 16 diseases/traits with AMD when controlling the FDR to be at $1 \%$ (Figs. 2 and 3). Three genetic scores related to autoimmunity (PSO, RA, and systemic lupus erythematosus [SLE]) were associated with increased risk for AMD, suggesting that participants at increased risk for autoimmune-related diseases are at higher risk for AMD. The remaining seven autoimmune-related genetic scores were consistent in trend (i.e. higher genetic scores are associated with higher AMD risk), although they failed to reach statistical significance. Similarly, we found increased AMD risk for higher genetic scores for elevated $\mathrm{C}$-reactive protein (CRP).
Interestingly, our findings revealed that participants with higher scores for cardiovascular diseases such as hypertension (HTN) or coronary artery disease (CAD) are at decreased risk for AMD. In line with this, participants with more alleles that increase blood pressure have a reduced risk of developing AMD. Furthermore, several scores related to adverse lipid levels in blood are associated with decreased AMD risk: participants with lower HDL genetic scores and higher LDL and total glycerol genetic scores were found to have decreased risk of AMD (Fig. 2). Participants with more alleles for higher bonemineral density levels in the femoral neck (BMDFN) have decreased risk for AMD. Although we did not find a consistent trend for the association of genetic scores of various types of cancer and AMD, we found that participants at higher genetic risk for cutaneous malignant melanoma (CMM) have an increased risk for AMD. This association can, however, not be attributed to a single variant in the CMM score, since none of the 20 variants used to calculate the score was individually found to be significantly associated with AMD.

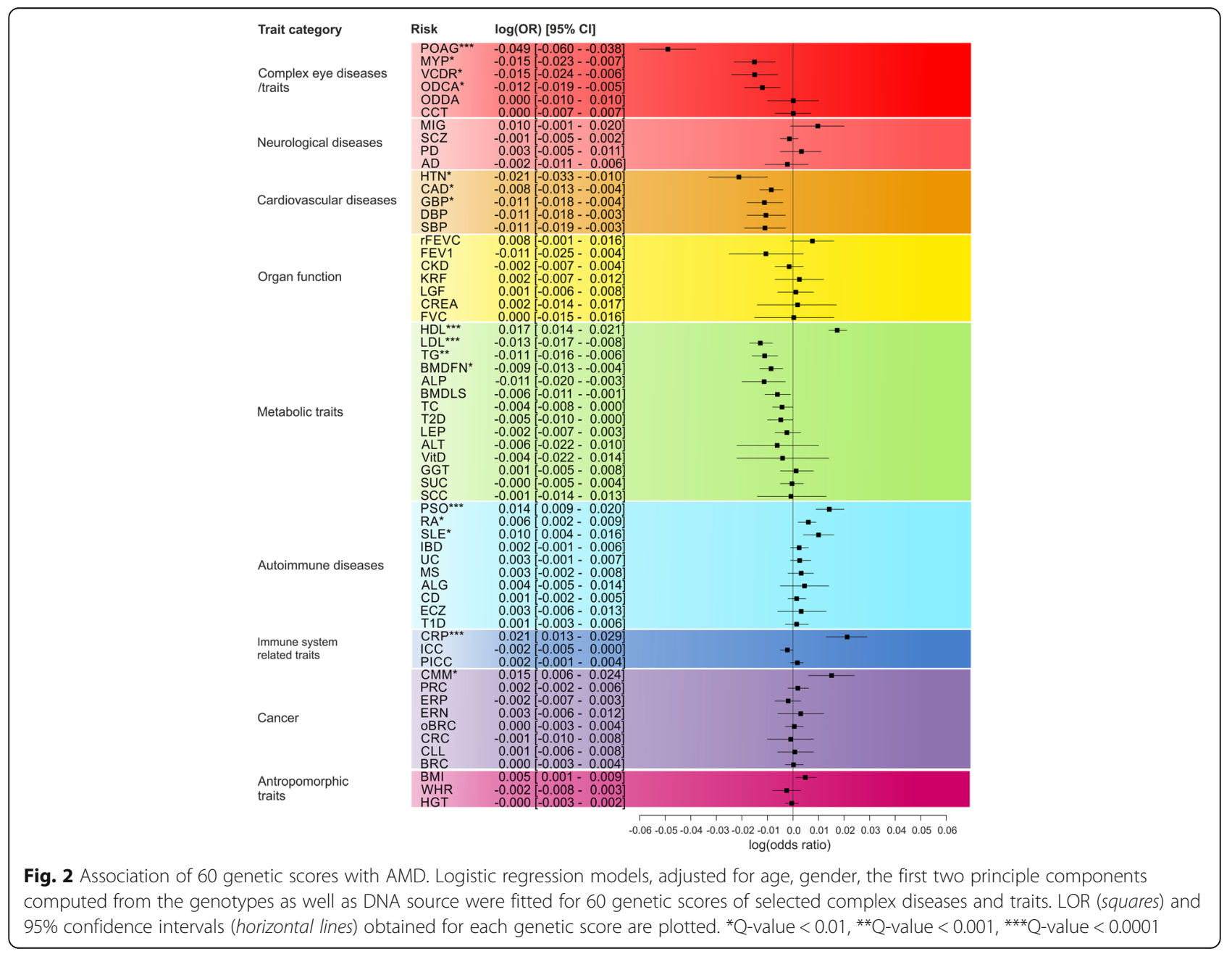




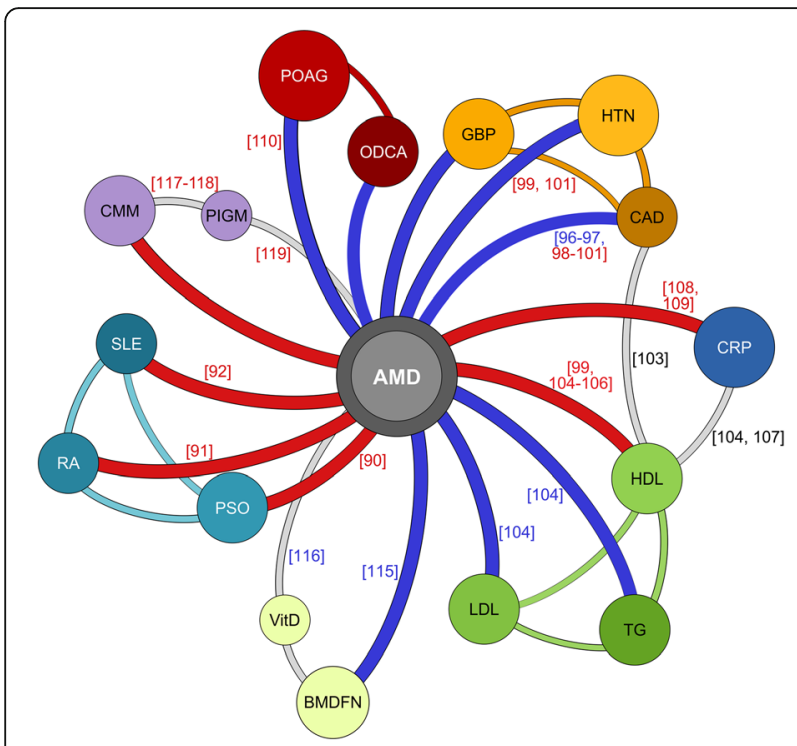

Fig. 3 Relationship between complex diseases/traits and AMD based on significant genetic score associations. Nodes represent diseases or traits and are colored according to uniform color scheme (see also Fig. 2 and Additional file 2: Table S1). The size of each node represents the effect size of the association with AMD. Diseases and traits within distinct disease categories (see also Fig. 2) are connected with lines colored according to the respective disease category. Lines connecting AMD and diseases/traits indicate the direction of the association with red lines indicating an adverse association and blue lines representing protective associations. Gray lines depict interactions according to literature which could not be confirmed by genetic scores or were not investigated within this study. The numbers in brackets indicate the references which either support or dispute the respective interaction. The colors of the numbers indicate whether the cited literature reported an adverse (red) or a protective (blue) interaction. In case a finding is novel, no literature reference is presented on a connection between nodes

Next, we investigated the association of genetic scores of eye-related diseases/traits with AMD risk (Fig. 2, Additional file 1: Figure S2). We found a highly significant association of the myopia genetic score with AMD revealing a strong protective effect. Similarly, AMD patients have fewer risk alleles generally implicated in POAG and related traits of the optic disc area (optic disc cup area [ODCA] and vertical cup to disc ratio [VCDR]). Since the controls of our study were largely recruited in ophthalmologic clinics, it is possible that the association of glaucoma genetic scores can be explained by an enrichment of individuals with glaucoma in our controls. We therefore investigated the association of the glaucoma and related genetic scores restricted to study participants from population-based (cross-sectional) studies. This analysis included 6412 individuals and revealed a consistent protective association of POAG and ODCA with AMD (Additional file 1: Figure S2). Of note, the association of VCDR and myopia (MYP) was markedly weaker in individuals recruited in population-based studies (Additional file 1: Figure S2).

\section{Association of candidate variants with AMD}

Given the association of genetic scores for several diseases with AMD risk indicating an overlap of various disease etiologies with AMD, we were interested to search for novel AMD-associated variants among those identified. Therefore, we analyzed the 1824 variants used for the calculation of the 60 scores for potential association with AMD risk. To account for multiple testing, we again controlled the FDR at 1\%. Consequently, 31 novel variants were found to be associated with AMD risk (Q-value < 0.01 , p values $1.07 \times 10^{-7}$ to $3.0 \times 10^{-4}$; Additional file 3 : Table S2). Moreover, this association was conditioned for 52 AMD-associated risk variants to exclude the significant association signals which may be due to linkage to any of the 52 known AMD associated variants. Following this adjustment, 28 variants remained significantly associated with AMD risk (Q-value < 0.01, Table 1).

Next, we extracted the variants correlated to the respective top variant at each locus $\left(R^{2}>0.5\right)$ and annotated these using the Variant Effect Predictor [88]. In total, we identified 12 non-synonymous and 13 synonymous variants (Table 2).

Finally, we defined AMD associated loci around the top variants with the boundaries comprising the most distant variant with $R^{2}>0.5$ and added a margin of $100 \mathrm{Kbp}$ to both boundaries. In total, the 28 novel variants defined 20 loci associated with late-stage AMD (Table 1) and thus implicated potential novel genes involved in disease risk. We extracted the genes located in the 20 novel and 34 known loci [7] and used INRICH to perform pathway enrichment analysis. This approach strengthens the notion that complement activation is the main pathway involved in AMD risk (Reactome NCBI Regulation of complement cascade: Q-value $=0.0006, \mathrm{GO}$ Regulation of complement activation: $\mathrm{Q}$-value $=0.002)$. No other pathway reached the significance threshold (Q-value $<0.01$, Additional file 4: Table S3).

\section{Discussion}

Here, we show an association of genetic scores of 16 different diseases/traits with late-stage AMD. Most notably, we found genetic scores of autoimmune diseases (PSO, $\mathrm{RA}$, and SLE), cardiovascular health (CAD, general blood pressure $[\mathrm{GBP}], \mathrm{HTN}$ ) and lipid levels (HDL, LDL, and triglyceride [TG]) to be associated with AMD. Remarkably, the genetic score for BMDFN as well as the genetic score for CMM were also associated with AMD. We also found that several genetic scores related to other ocular diseases (POAG, VCDR, MYP, and ODCA) are associated with AMD risk. Under the assumption that a genetic score summarizes the known genetic factors for a disease/trait, we conclude that these 16 diseases/traits share etiological properties with AMD.

Our findings point to two major areas of interest. First, we demonstrate that genetic scores related to autoimmunity are 


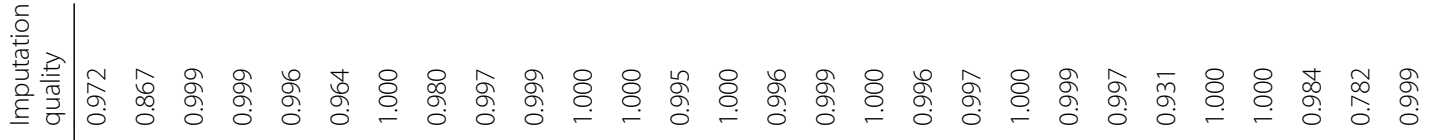

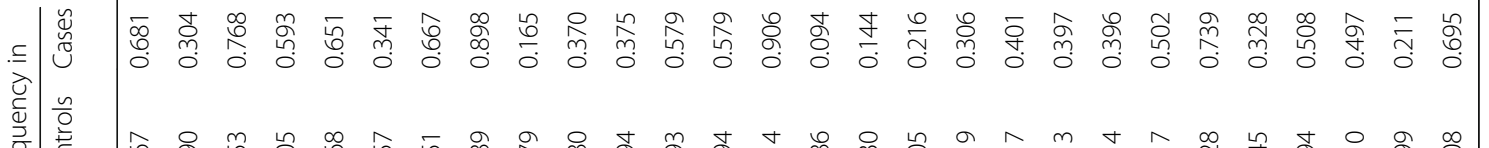

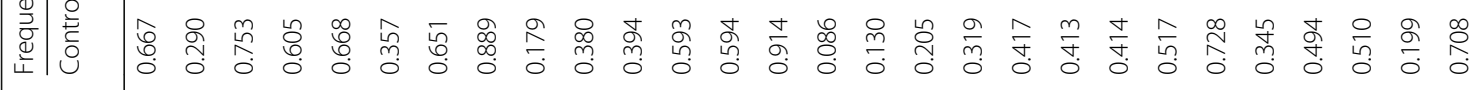

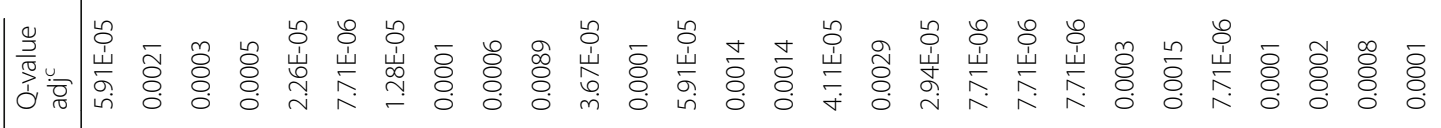

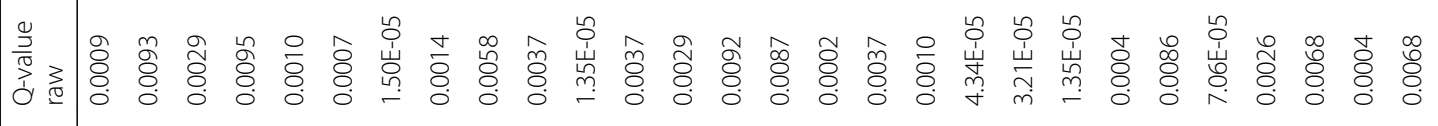

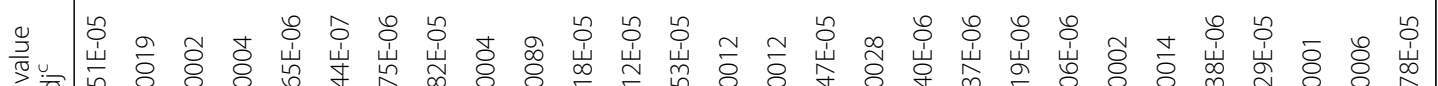

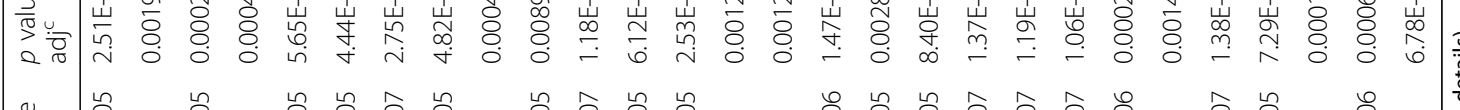

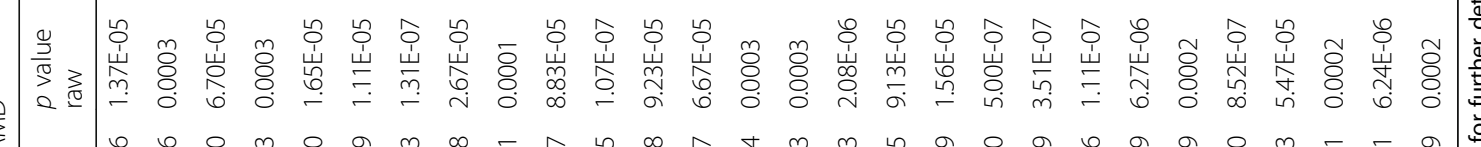

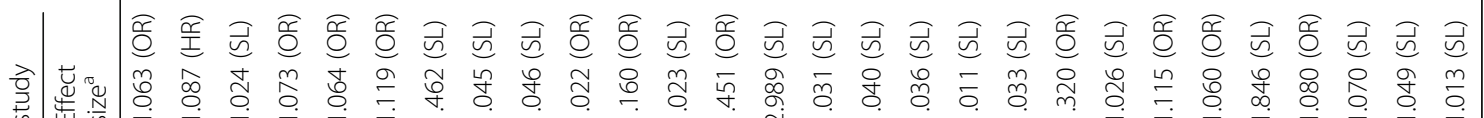

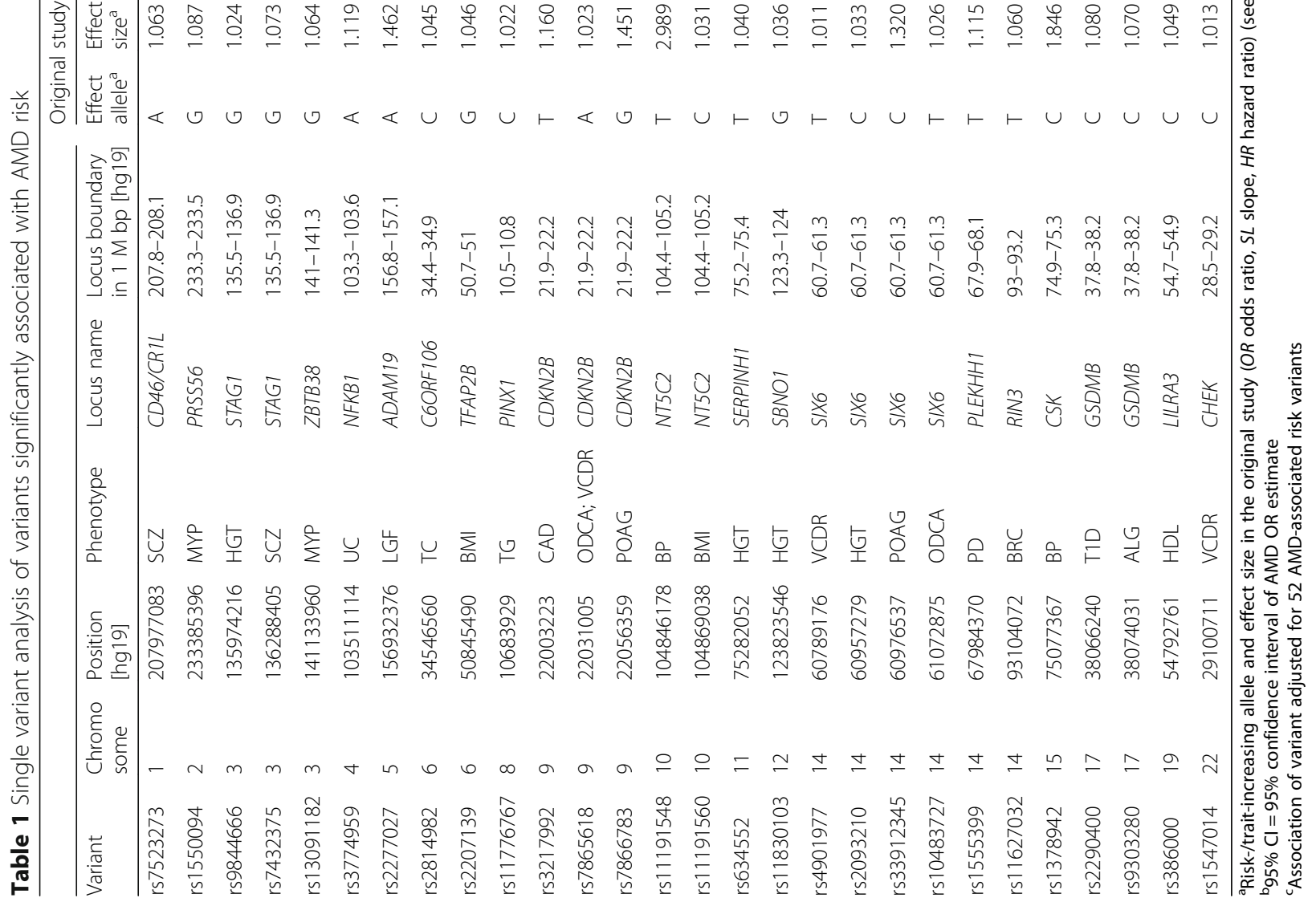


Table 2 Coding variants in novel AMD-associated loci

\begin{tabular}{|c|c|c|c|c|c|c|c|c|c|c|}
\hline Variant & $\begin{array}{l}\text { Top } \\
\text { variant }\end{array}$ & Chromosome & $\begin{array}{l}\text { Position } \\
\text { [hg19] }\end{array}$ & $\begin{array}{l}r^{2} \text { to top } \\
\text { variant }\end{array}$ & $\begin{array}{l}\text { Frequency } \\
\text { of variant }\end{array}$ & $\begin{array}{l}\text { Affected } \\
\text { gene }\end{array}$ & Consequence & Phenotype & $\begin{array}{l}\text { Locus } \\
\text { name }\end{array}$ & $\begin{array}{l}\text { Locus boundary } \\
\text { in } 1 \mathrm{M} \mathrm{bp} \mathrm{[hg19]}\end{array}$ \\
\hline rs6683902 & rs7523273 & 1 & 207881557 & 0.545 & 0.563 & CR1L & p.1455V & SCZ & CD46/CR1L & 207.8-208.1 \\
\hline rs2796257 & rs7523273 & 1 & 207890866 & 0.549 & 0.434 & CR1L & p.L491P & SCZ & CD46/CR1L & 207.8-208.1 \\
\hline rs1550094 & rs1550094 & 2 & 233385396 & 1.000 & 0.310 & PRSS56 & p.A30T & MYP & PRSS56 & 233.3-233.5 \\
\hline rs9860801 & rs9844666 & 3 & 136088038 & 0.547 & 0.302 & STAG1 & p.F403F & HGT & STAG1 & 135.5-136.9 \\
\hline rs1052620 & rs9844666 & 3 & 136574521 & 0.956 & 0.189 & SLC35G2 & p.L407L & HGT & STAG1 & $135.5-136.9$ \\
\hline rs1422795 & rs2277027 & 5 & 156936364 & 0.996 & 0.357 & ADAM19 & p.S17G & LGF & ADAM19 & 156.8-157.1 \\
\hline rs943037 & rs11191548 & 10 & 104835919 & 0.988 & 0.088 & CNNM2 & p.A770A & $\mathrm{BP}$ & NT5C2 & $104.4-105.2$ \\
\hline rs584961 & rs634552 & 11 & 75277628 & 0.625 & 0.888 & SERPINH1 & p.L78L & HGT & SERPINH1 & $75.2-75.4$ \\
\hline rs12811109 & rs11830103 & 12 & 123471094 & 0.838 & 0.216 & PITPNM2 & p.H1205H & HGT & SBNO1 & $123.3-124$ \\
\hline rs1051431 & rs11830103 & 12 & 123645803 & 0.878 & 0.768 & MPHOSPH9 & p.Y935H & HGT & SBNO1 & $123.3-124$ \\
\hline rs6488868 & rs11830103 & 12 & 123799974 & 0.756 & 0.722 & SBNO1 & p.G1022G & HGT & SBNO1 & $123.3-124$ \\
\hline rs1060105 & rs11830103 & 12 & 123806219 & 0.988 & 0.223 & SBNO1 & p.S729N & HGT & SBNO1 & $123.3-124$ \\
\hline rs61388686 & rs11830103 & 12 & 123810873 & 0.591 & 0.664 & SBNO1 & p.1567| & HGT & SBNO1 & $123.3-124$ \\
\hline rs12322888 & rs11830103 & 12 & 123825559 & 1.000 & 0.225 & SBNO1 & p.K209K & HGT & SBNO1 & $123.3-124$ \\
\hline rs1254319 & rs10483727 & 14 & 60903757 & 0.613 & 0.301 & C14orf39 & p.L524F & ODCA & SIX6 & $60.7-61.3$ \\
\hline rs33912345 & rs10483727 & 14 & 60976537 & 0.978 & 0.597 & SIX6 & p.H141N & ODCA & SIX6 & $60.7-61.3$ \\
\hline rs117068593 & rs11627032 & 14 & 93118229 & 0.565 & 0.187 & RIN3 & p.R279C & $\mathrm{BRC}$ & RIN3 & $60.7-61.3$ \\
\hline rs2470890 & rs1378942 & 15 & 75047426 & 0.843 & 0.596 & CYP1A2 & p.N516N & $\mathrm{BP}$ & CSK & $74.9-75.3$ \\
\hline rs4886615 & rs1378942 & 15 & 75131661 & 0.553 & 0.691 & ULK3 & p.A302A & $\mathrm{BP}$ & CSK & $74.9-75.3$ \\
\hline rs907092 & rs2290400 & 17 & 37922259 & 0.761 & 0.473 & IKZF3 & p.S399s & T1D & GSDMB & $37.8-38.2$ \\
\hline rs11557466 & rs2290400 & 17 & 38024626 & 0.792 & 0.472 & ZPBP2 & p.L7L & T1D & GSDMB & $37.8-38.2$ \\
\hline rs11557467 & rs2290400 & 17 & 38028634 & 0.924 & 0.508 & ZPBP2 & p.S55l & T1D & GSDMB & $37.8-38.2$ \\
\hline rs10852935 & rs2290400 & 17 & 38031674 & 0.792 & 0.472 & ZPBP2 & p.C174C & T1D & GSDMB & $37.8-38.2$ \\
\hline rs2305480 & rs2290400 & 17 & 38062196 & 0.815 & 0.466 & GSDMB & p.P302S & T1D & GSDMB & $37.8-38.2$ \\
\hline rs2305479 & rs2290400 & 17 & 38062217 & 0.948 & 0.502 & GSDMB & p.G295R & T1D & GSDMB & $37.8-38.2$ \\
\hline
\end{tabular}

associated with $\mathrm{AMD}$ with adverse effects, in agreement with the observation that the presence of either PSO, RA, or SLE resulted in a higher risk for AMD [90-92]. Overall, all of the autoimmunity-related scores were higher in AMD patients than in controls. This strengthens the notion that AMD greatly overlaps with or possibly is an autoimmune-related disease. It remains to be seen whether these patients at risk for AMD might profit from anti-inflammatory or immunosuppressive medication [93-95].

Second, individuals with increased genetic risk for cardiovascular disease and related traits have a lower risk for AMD, which could potentially be explained by a survival bias since our cases are on average two years older than our controls. Nevertheless, by adjusting for gender and age, we should be able to account for the findings. Still, we find a strong association of cardiovascular disease traits with AMD. Such a protective effect of cardiovascular-related genetic scores for AMD is in line with previous results [96, 97], despite disparate reports by other groups [98-101]. The latter discordance may be explained by factors other than genetic influences on cardiovascular disease risk and such factors may be elevated in late-stage AMD patients. For example, it has long been recognized that HDL plays a crucial role in preventing cardiovascular disease and is believed to be neuroprotective while reducing the risk for other neuropathies, e.g. Alzheimer's disease [102] due to anti-inflammatory and anti-oxidant properties [103]. According to our findings, AMD patients should have higher HDL, lower LDL, and lower total glycerol levels in their serum compared with controls, well in agreement with published data [104-106]. On another note, high levels of HDL and low total glycerol have been correlated with increased complement activation [104, 107]. This could explain the observed association where variants causing high HDL levels are also associated with increased CRP levels in serum [104], additionally increasing complement activation levels [55]. This is in line with the observation that elevated CRP levels are a risk factor for AMD $[108,109]$. The risk for AMD may be increased by the same factors due to increased complement activation.

The association of genetic scores of ocular traits with AMD requires a more in-depth consideration. While the 
genetic scores for central cornea thickness (CCT) and ODDA are not associated with AMD, the remaining genetic scores associated with glaucoma (POAG, ODCA, and VCDR) as well as the genetic score for myopia were protective for AMD. Under the assumption that our controls are enriched for glaucoma and myopia cases, a conceivable expectation for a hospital-based recruitment of controls, the identified association could be explained but would render this finding an artefact. Controls are often enrolled as patients visiting the clinic for reasons other than AMD and may thus be enriched for other prevalent ocular diseases. Furthermore, AMD cases with myopia may be less frequently recruited since grading of AMD can be difficult in the presence of high myopia. Consequently, there may be fewer myopia patients in the patient cohort. On the other hand, population-based studies, i.e. studies randomly recruiting patients and controls in a community setting, should not be compromised by an enrichment of any ocular disease unless they share a similar genetic or non-genetic risk. Testing our dataset for this possibility showed that the association of the genetic scores in the population-based studies remained unchanged when comparing to the entire data including case-control studies with the exception of the VCDR and MYP genetic scores. From this, we conclude that AMD patients indeed have a genetically reduced risk to develop open angle glaucoma, although a smaller study found an adverse relationship between AMD and POAG using summary statistics [110]. Conversely, we found no association of the myopia genetic score with AMD in our dataset in the population-based studies, in line with previous reports [111-114].

A surprising finding was the association of bonemineral density genetic scores with AMD. Both scores of bone-mineral density (in the femoral neck and in the lumbar spine) are nominally significant, suggesting a protective effect for AMD in individuals having a higher bone-mineral density. Interestingly, vitamin $\mathrm{D}$ deficiency was linked to incident AMD in the CARED study [115] and bone-mineral density can be increased with vitamin D supplementation [116]. Of note, neither the genetic score of serum calcium concentration nor vitamin D concentration was found to be significantly associated with AMD. Nevertheless, these findings could point to future studies that explore vitamin D and calcium supplementation to prevent AMD.

The significant association of CMM with AMD is not due to a single variant associated with both diseases, as none of the 20 variants used for the calculation of the genetic score by itself was significantly associated with AMD. The effect seems to result from an accumulation of all 20 variant effect sizes (mean $L O R=0.018$ ). A possible explanation may be that pigmentation plays a role in both diseases. CMM is a cancer type affecting the skin and associations with different characteristics of pigmentation are described [117]. In general, people with lighter skin have a higher melanoma risk [118]. This is in accordance with observations that Caucasians are more likely to be affected by AMD compared with black individuals [119].

Our candidate variant approach was restricted to variants significantly associated with other diseases/traits and revealed 20 novel AMD-associated loci with 28 AMD associated variants. These variants have been implicated in other diseases/traits with genome-wide significance and therefore represent compelling novel findings, although these novel loci do not harbor genes that provide insights into so far unknown AMDassociated pathways. However, the newly identified loci strengthen the notion that AMD disease is extensively related to pathologic complement activation with the discovery that variants in the CD46/CR1L locus are significantly associated with AMD. In subsequent studies, in-depth bioinformatics and molecular evaluation of these risk signals need to be performed, particularly in the light of pathways and mechanisms associated with both AMD and the relevant disease/trait.

The results of this study are in accordance with the antagonistic pleiotropy theory of aging [120], which states that many pleiotropic genetic factors are beneficial at younger ages (by either increasing fecundity or survival) while possibly unfavorable later in life by influencing senescence and thus age-related disease processes [121]. We speculate that this could also be true for pleiotropic variants associated with AMD. For instance, increased immune activity could be advantageous at younger ages by reducing the risk for infections, but could ultimately lead to self-tissue damage causing autoimmune disease and late-stage AMD. Similarly, increased HDL and lower LDL levels result in improved cardiovascular health, which is an important factor to survive to old age. However, these same processes can cause late-stage AMD and might persist in populations due to a lack of negative selection in the elderly. As a consequence, our findings challenge the prospects of gene/genome manipulations to target a selected complex disease or trait, since seemingly beneficial genetic manipulations targeting a specific disease might in fact result in a seemingly unrelated disease at old age or accelerate aging in consequence.

\section{Conclusions}

Our findings suggest a substantial overlap of the genetics of autoimmune diseases, cardiovascular traits, lipid metabolism, cancer and metabolic traits as well as other eye-related diseases and traits with AMD. Investigating the association of variants associated with other diseases proves worthwhile to identify novel AMD risk variants and further implicates the complement system as the major pathway involved in AMD pathology. 


\section{Additional files}

Additional file 1: Figures. Supplementary Figures S1 and S2 with Figure Legends. (PDF 1935 kb)

Additional file 2: Table S1. Characteristics of diseases/traits included in the study. (XLSX $22 \mathrm{~kb}$ )

Additional file 3: Table S2. Detailed list of the genetic variants extracted from all studies. Contains multiple tabs. (XLSX $671 \mathrm{~kb}$ )

Additional file 4: Table S3. Pathway enrichment analysis results and parameters. (XLSX $14 \mathrm{~kb}$ )

\section{Acknowledgements}

The authors thank the International AMD Genomics Consortium (IAMDGC, http:// eaglep.case.edu/iamdgc_web/) for providing the genotypes. They also thank Paul N. Baird (Centre for Eye Research Australia, University of Melbourne, Royal Victorian Eye and Ear Hospital, Australia), Michael B. Gorin (Department of Ophthalmology, David Geffen School of Medicine, Stein Eye Institute, University of California, USA), Jie Jin Wang (Centre for Vision Research, Department of Ophthalmology and Westmead Millennium Institute for Medical Research, University of Sydney, Australia), and Ron Klein (Department of Ophthalmology and Visual Sciences, University of Wisconsin School of Medicine and Public Health, USA) from the IAMDGC for their critical comments on the final manuscript.

The International AMD Genomics Consortium (IAMDGC) is a collaboration group with the following individual members:

Lars G Fritsche, Wilmar Igl, Jessica N Cooke Bailey, Felix Grassmann, Sebant Sengupta, Jennifer L Bragg-Gresham, Kathryn P Burdon, Scott J Hebbring, Cindy Wen, Mathias Gorski, Ivana K Kim, David Cho, Donald Zack, Eric Souied, Hendrik P N Scholl, Elisa Bala, Kristine E Lee, David J Hunter, Rebecca J Sardell, Paul Mitchell, Joanna E Merriam, Valentina Cipriani, Joshua D Hoffman, Tina Schick, Yara T E Lechanteur, Robyn H Guymer, Matthew P Johnson, Yingda Jiang, Chloe M Stanton, Gabriëlle H S Buitendijk, Xiaowei Zhan, Alan M Kwong, Alexis Boleda, Matthew Brooks, Linn Gieser, Rinki Ratnapriya, Kari E Branham, Johanna R Foerster, John R Heckenlively, Mohammad I Othman, Brendan J Vote, Helena Hai Liang, Emmanuelle Souzeau, lan L McAllister, Timothy Isaacs, Janette Hall, Stewart Lake, David A Mackey, lan J Constable, Jamie E Craig, Terrie E Kitchner, Zhenglin Yang, Zhiguang Su, Hongrong Luo, Daniel Chen, Hong Ouyang, Ken Flagg, Danni Lin, Guanping Mao, Henry Ferreyra, Klaus Stark, Claudia N von Strachwitz, Armin Wolf, Caroline Brandl, Guenther Rudolph, Matthias Olden, Margaux A Morrison, Denise J Morgan, Matthew Schu, Jeeyun Ahn, Giuliana Silvestri, Evangelia E Tsironi, Kyu Hyung Park, Lindsay A Farrer, Anton Orlin, Alexander Brucker, Mingyao Li, Christine A Curcio, Saddek Mohand-Saïd, José-Alain Sahel, Isabelle Audo, Mustapha Benchaboune, Angela J Cree, Christina A Rennie, Srinivas V Goverdhan, Michelle Grunin, Shira Hagbi-Levi, Peter Campochiaro, Nicholas Katsanis, Frank G Holz, Frédéric Blond, Hélène Blanché, Jean-François Deleuze, Robert P Igo Jr, Barbara Truitt, Neal S Peachey, Stacy M Meuer, Chelsea E Myers, Emily L Moore, Ronald Klein, Michael A Hauser, Eric A Postel, Monique D Courtenay, Stephen G Schwartz, Jaclyn L Kovach, William K Scott, Gerald Liew, Ava G Tan, Bamini Gopinath, John C Merriam, R Theodore Smith, Jane C Khan, Humma Shahid, Anthony T Moore, J Allie McGrath, Reneé Laux, Milam A Brantley Jr, Anita Agarwal, Lebriz Ersoy, Albert Caramoy, Thomas Langmann, Nicole T M Saksens, Eiko K de Jong, Carel B Hoyng, Melinda S Cain, Andrea J Richardson, Tammy M Martin, John Blangero, Daniel E Weeks, Bal Dhillon, Cornelia M van Duijn, Kimberly F Doheny, Jane Romm, Caroline C W Klaver, Caroline Hayward, Michael B Gorin, Michael L Klein, Paul N Baird, Anneke I den Hollander, Sascha Fauser, John R W Yates, Rando Allikmets, Jie Jin Wang, Debra A Schaumberg, Barbara E K Klein, Stephanie A Hagstrom, Itay Chowers, Andrew J Lotery, Thierry Léveillard, Kang Zhang, Murray H Brilliant, Alex W Hewitt, Anand Swaroop, Emily Y Chew, Margaret A Pericak-Vance, Margaret DeAngelis, Dwight Stambolian, Jonathan L Haines, Sudha K Iyengar, Bernhard H F Weber, Gonçalo R Abecasis \& Iris M Heid.

\section{Funding}

This study was supported in parts by the Deutsche Forschungsgemeinschaft (WE 1259/19-1 and WE 1259/19-2 to BHFW), the Alcon Research Institute (to BHFW), and by grants from the German Federal Ministry of Education and Research (BMBF 01ER1206 and 01ER1507 to IMH). Genotyping was conducted as part of the IAMDGC exome-chip project supported by CIDR (contract number HHSN268201200008I) and funded by EY022310 (to Jonathan L. Haines, Case Western Reserve University, Cleveland) and 1X01HG006934-01 (to Gonçalo R. Abecasis, University of Michigan, Department of Biostatistics). The funding bodies had no role in the design of the study and collection, analysis, and interpretation of data and in writing the manuscript.

\section{Availability of data and materials}

The dataset compiled from 16,144 people with late-stage AMD (NV, GA, or both GA/NV AMD) and 17,832 control individuals without AMD from 26 studies are available at the database of genotypes and phenotypes (dbGaP) under the accession number phs001039 (URL: https://www.ncbi.nlm.nih.gov/ projects/gap/cgi-bin/study.cgi?study_id=phs001039.v1.p1). Publicly available data from genome-wide association studies (GWAS) of human diseases and traits were extracted from the respective publications. The relevant PubMed identifiers of those publications are listed in Additional file 2: Table S1.

\section{Authors' contributions}

FG and BHFW made substantial contributions to conception and design of the study; CK and IAMDGC provided the genetic data; FG, CK, MEZ, MG, VG, and $\mathrm{KS}$ devised the methodology and analyzed the clinical and genetic data; MG, KS, and IMH assessed the overall reproducibility of the results; FG, CK, $\mathrm{IMH}$, and BHFW wrote the manuscript with input from all authors. All authors have given final approval of the version to be published.

\section{Competing interests}

The authors declare that they have no competing interests.

\section{Consent for publication}

Not applicable

\section{Ethics approval and consent to participate}

At the participating sites the study was conducted in strict adherence to the tenets of the Declaration of Helsinki and was approved by the respective local Ethics Committees (see also reference [13]).

\section{Publisher's Note}

Springer Nature remains neutral with regard to jurisdictional claims in published maps and institutional affiliations.

\section{Author details}

${ }^{1}$ Institute of Human Genetics, University of Regensburg, Franz-Josef-Strauss-Allee 11 , 93053 Regensburg, Germany. ${ }^{2}$ Department of Genetic Epidemiology, University of Regensburg, Franz-Josef-Strauss-Allee 11, 93053 Regensburg, Germany. ${ }^{3}$ Institute of Medical Microbiology and Hygiene, University of Regensburg, Franz-Josef-Strauss-Allee 11, Regensburg 93053, Germany.

Received: 1 November 2016 Accepted: 2 March 2017

Published online: 27 March 2017

\section{References}

1. Grassmann F, Ach T, Brandl C, Heid IM, Weber BHF. What does genetics tell us about age-related macular degeneration? Annu Rev Vis Sci. 2015;1:73-96.

2. Friedman DS, O'Colmain BJ, Muñoz B, Tomany SC, McCarty C, de Jong PTVM, et al. Prevalence of age-related macular degeneration in the United States. Arch Ophthalmol. 2004;122:564-72.

3. Wong WL, Su X, Li X, Cheung CMG, Klein R, Cheng C-Y, et al. Global prevalence of age-related macular degeneration and disease burden projection for 2020 and 2040: a systematic review and meta-analysis. Lancet Glob Health. 2014;2:e106-16.

4. Ferris FL, Davis MD, Clemons TE, Lee L-Y, Chew EY, Lindblad AS, et al. A simplified severity scale for age-related macular degeneration: AREDS Report No. 18. Arch Ophthalmol. 2005;123:1570-4.

5. Swaroop A, Branham KE, Chen W, Abecasis G. Genetic susceptibility to agerelated macular degeneration: a paradigm for dissecting complex disease traits. Hum Mol Genet. 2007;16(Spec No):R174-82.

6. Grassmann F, Fleckenstein M, Chew EY, Strunz T, Schmitz-Valckenberg S, Göbel AP, et al. Clinical and genetic factors associated with progression of geographic atrophy lesions in age-related macular degeneration. PLoS One. 2015:10:e0126636.

7. Fritsche LG, Fariss RN, Stambolian D, Abecasis GR, Curcio CA, Swaroop A. Age-related macular degeneration: genetics and biology coming together Annu Rev Genomics Hum Genet. 2014;15:151-71. 
8. Gold B, Merriam JE, Zernant J, Hancox LS, Taiber AJ, Gehrs K, et al. Variation in factor $\mathrm{B}$ (BF) and complement component 2 (C2) genes is associated with age-related macular degeneration. Nat Genet. 2006;38:458-62.

9. Hageman GS, Anderson DH, Johnson LV, Hancox LS, Taiber AJ, Hardisty LI, et al. A common haplotype in the complement regulatory gene factor $\mathrm{H}$ (HF1/CFH) predisposes individuals to age-related macular degeneration. Proc Natl Acad Sci U S A. 2005;102:7227-32.

10. Seddon JM, Yu Y, Miller EC, Reynolds R, Tan PL, Gowrisankar S, et al. Rare variants in CFI, C3 and C9 are associated with high risk of advanced agerelated macular degeneration. Nat Genet. 2013;45:1366-70.

11. Zhan X, Larson DE, Wang C, Koboldt DC, Sergeev W, Fulton RS, et al. Identification of a rare coding variant in complement 3 associated with agerelated macular degeneration. Nat Genet. 2013;45:1375-9.

12. Grassmann F, Cantsilieris S, Schulz-Kuhnt A-S, White SJ, Richardson AJ, Hewitt AW, et al. Multiallelic copy number variation in the complement component 4A (C4A) gene is associated with late-stage age-related macular degeneration (AMD). J Neuroinflammation. 2016;13:81.

13. Fritsche LG, Igl W, Bailey JNC, Grassmann F, Sengupta S, Bragg-Gresham JL, et al. A large genome-wide association study of age-related macular degeneration highlights contributions of rare and common variants. Nat Genet. 2016;48:134-43.

14. Grassmann F, Fritsche LG, Keilhauer CN, Heid IM, Weber BHF. Modelling the genetic risk in age-related macular degeneration. PLoS One. 2012;7:e37979.

15. Lu Y, Vitart V, Burdon KP, Khor CC, Bykhovskaya Y, Mirshahi A, et al. Genome-wide association analyses identify multiple loci associated with central corneal thickness and keratoconus. Nat Genet. 2013;45:155-63.

16. Kiefer AK, Tung JY, Do CB, Hinds DA, Mountain JL, Francke U, et al. Genomewide analysis points to roles for extracellular matrix remodeling, the visual cycle, and neuronal development in myopia. PLoS Genet. 2013;9:e1003299.

17. Springelkamp H, Mishra A, Hysi PG, Gharahkhani P, Höhn R, Khor C-C, et al. Meta-analysis of genome-wide association studies identifies novel loci associated with optic disc morphology. Genet Epidemiol. 2015;39:207-16.

18. Bailey JNC, Loomis SJ, Kang JH, Allingham RR, Gharahkhani P, Khor CC, et al. Genome-wide association analysis identifies TXNRD2, ATXN2 and FOXC1 as susceptibility loci for primary open-angle glaucoma. Nat Genet. 2016;48:189-94.

19. Springelkamp H, Höhn R, Mishra A, Hysi PG, Khor C-C, Loomis SJ, et al. Metaanalysis of genome-wide association studies identifies novel loci that influence cupping and the glaucomatous process. Nat Commun. 2014;5:4883.

20. Anttila V, Winsvold BS, Gormley P, Kurth T, Bettella F, McMahon G, et al. Genome-wide meta-analysis identifies new susceptibility loci for migraine. Nat Genet. 2013;45:912-7.

21. Nalls MA, Pankratz N, Lill CM, Do CB, Hernandez DG, Saad M, et al. Largescale meta-analysis of genome-wide association data identifies six new risk loci for Parkinson's disease. Nat Genet. 2014;46:989-93.

22. Schizophrenia Working Group of the Psychiatric Genomics Consortium. Biological insights from 108 schizophrenia-associated genetic loci. Nature. 2014;511:421-7.

23. CARDIoGRAMplusC4D Consortium, Deloukas P, Kanoni S, Willenborg C, Farrall M, Assimes TL, et al. Large-scale association analysis identifies new risk loci for coronary artery disease. Nat Genet. 2013:45:25-33.

24. International Consortium for Blood Pressure Genome-Wide Association Studies, Ehret GB, Munroe PB, Rice KM, Bochud M, Johnson AD, et al. Genetic variants in novel pathways influence blood pressure and cardiovascular disease risk. Nature. 2011:478:103-9.

25. Köttgen A, Glazer NL, Dehghan A, Hwang S-J, Katz R, Li M, et al. Multiple loci associated with indices of renal function and chronic kidney disease. Nat Genet. 2009;41:712-7.

26. Köttgen A, Pattaro C, Böger CA, Fuchsberger C, Olden M, Glazer NL, et al. New loci associated with kidney function and chronic kidney disease. Nat Genet. 2010:42:376-84

27. Soler Artigas M, Loth DW, Wain LV, Gharib SA, Obeidat M, Tang W, et al. Genome-wide association and large-scale follow up identifies 16 new loci influencing lung function. Nat Genet. 2011:43:1082-90.

28. Loth DW, Soler Artigas M, Gharib SA, Wain LV, Franceschini N, Koch B, et al. Genome-wide association analysis identifies six new loci associated with forced vital capacity. Nat Genet. 2014;46:669-77.

29. Repapi E, Sayers I, Wain LV, Burton PR, Johnson T, Obeidat M, et al. Genome-wide association study identifies five loci associated with lung function. Nat Genet. 2010;42:36-44.

30. Hancock DB, Eijgelsheim M, Wilk JB, Gharib SA, Loehr LR, Marciante KD, et al. Meta-analyses of genome-wide association studies identify multiple loci associated with pulmonary function. Nat Genet. 2010;42:45-52.
31. Estrada K, Styrkarsdottir U, Evangelou E, Hsu Y-H, Duncan EL, Ntzani EE, et al. Genome-wide meta-analysis identifies 56 bone mineral density loci and reveals 14 loci associated with risk of fracture. Nat Genet. 2012;44:491-501.

32. Chambers JC, Zhang W, Sehmi J, Li X, Wass MN, Van der Harst $P$, et al. Genome-wide association study identifies loci influencing concentrations of liver enzymes in plasma. Nat Genet. 2011;43:1131-8.

33. Global Lipids Genetics Consortium, Willer CJ, Schmidt EM, Sengupta S, Peloso GM, Gustafsson S, et al. Discovery and refinement of loci associated with lipid levels. Nat Genet. 2013;45:1274-83.

34. O'Seaghdha CM, Wu H, Yang Q, Kapur K, Guessous I, Zuber AM, et al. Metaanalysis of genome-wide association studies identifies six new Loci for serum calcium concentrations. PLoS Genet. 2013;9:e1003796.

35. Köttgen A, Albrecht E, Teumer A, Vitart V, Krumsiek J, Hundertmark C, et al. Genome-wide association analyses identify 18 new loci associated with serum urate concentrations. Nat Genet. 2013:45:145-54.

36. Morris AP, Voight BF, Teslovich TM, Ferreira T, Segrè AV, Steinthorsdottir V, et al. Large-scale association analysis provides insights into the genetic architecture and pathophysiology of type 2 diabetes. Nat Genet. 2012;44:981-90.

37. DIAbetes Genetics Replication And Meta-analysis (DIAGRAM) Consortium, Asian Genetic Epidemiology Network Type 2 Diabetes (AGEN-T2D) Consortium, South Asian Type 2 Diabetes (SAT2D) Consortium, Mexican American Type 2 Diabetes (MAT2D) Consortium, Type 2 Diabetes Genetic Exploration by Nex-generation sequencing in muylti-Ethnic Samples (T2DGENES) Consortium, Mahajan A, et al. Genome-wide trans-ancestry metaanalysis provides insight into the genetic architecture of type 2 diabetes susceptibility. Nat Genet. 2014;46:234-44.

38. Wang TJ, Zhang F, Richards JB, Kestenbaum B, van Meurs JB, Berry D, et al. Common genetic determinants of vitamin $D$ insufficiency: a genome-wide association study. Lancet. 2010;376:180-8.

39. Hinds DA, McMahon G, Kiefer AK, Do CB, Eriksson N, Evans DM, et al. A genome-wide association meta-analysis of self-reported allergy identifies shared and allergy-specific susceptibility loci. Nat Genet. 2013;45:907-11.

40. Jostins L, Ripke S, Weersma RK, Duerr RH, McGovern DP, Hui KY, et al. Hostmicrobe interactions have shaped the genetic architecture of inflammatory bowel disease. Nature. 2012;491:119-24.

41. Paternoster L, Standl M, Waage J, Baurecht H, Hotze M, Strachan DP, et al. Multiancestry genome-wide association study of 21,000 cases and 95,000 controls identifies new risk loci for atopic dermatitis. Nat Genet. 2015;47:1449-56.

42. International Multiple Sclerosis Genetics Consortium, Wellcome Trust Case Control Consortium 2, Sawcer S, Hellenthal G, Pirinen M, Spencer CCA, et al. Genetic risk and a primary role for cell-mediated immune mechanisms in multiple sclerosis. Nature. 2011:476:214-9.

43. Okada Y, Wu D, Trynka G, Raj T, Terao C, Ikari K, et al. Genetics of rheumatoid arthritis contributes to biology and drug discovery. Nature. 2014;506:376-81.

44. Suzuki A, Yamada R, Kochi Y, Sawada T, Okada Y, Matsuda K, et al. Functional SNPs in CD244 increase the risk of rheumatoid arthritis in a Japanese population. Nat Genet. 2008;40:1224-9.

45. Okada Y, Terao C, Ikari K, Kochi Y, Ohmura K, Suzuki A, et al. Meta-analysis identifies nine new loci associated with rheumatoid arthritis in the Japanese population. Nat Genet. 2012;44:511-6.

46. Eyre S, Bowes J, Diogo D, Lee A, Barton A, Martin P, et al. High-density genetic mapping identifies new susceptibility loci for rheumatoid arthritis. Nat Genet. 2012;44:1336-40.

47. Terao C, Yamada R, Ohmura K, Takahashi M, Kawaguchi T, Kochi Y, et al. The human AIRE gene at chromosome 21q22 is a genetic determinant for the predisposition to rheumatoid arthritis in Japanese population. Hum Mol Genet. 2011;20:2680-5.

48. Bentham J, Morris DL, Cunninghame Graham DS, Pinder CL, Tombleson P, Behrens TW, et al. Genetic association analyses implicate aberrant regulation of innate and adaptive immunity genes in the pathogenesis of systemic lupus erythematosus. Nat Genet. 2015;47:1457-64.

49. Bradfield JP, Qu H-Q, Wang K, Zhang H, Sleiman PM, Kim CE, et al. A genome-wide meta-analysis of six type 1 diabetes cohorts identifies multiple associated loci. PLoS Genet. 2011;7:e1002293.

50. Cooper JD, Smyth DJ, Smiles AM, Plagnol V, Walker NM, Allen JE, et al. Meta-analysis of genome-wide association study data identifies additional type 1 diabetes risk loci. Nat Genet. 2008:40:1399-401.

51. Hakonarson H, Grant SFA, Bradfield JP, Marchand L, Kim CE, Glessner JT, et al. A genome-wide association study identifies KIAA0350 as a type 1 diabetes gene. Nature. 2007;448:591-4. 
52. Todd JA, Walker NM, Cooper JD, Smyth DJ, Downes K, Plagnol V, et al. Robust associations of four new chromosome regions from genome-wide analyses of type 1 diabetes. Nat Genet. 2007;39:857-64.

53. Barrett JC, Clayton DG, Concannon P, Akolkar B, Cooper JD, Erlich HA, et al. Genome-wide association study and meta-analysis find that over 40 loci affect risk of type 1 diabetes. Nat Genet. 2009:41:703-7.

54. Wallace C, Smyth DJ, Maisuria-Armer M, Walker NM, Todd JA, Clayton DG. The imprinted DLK1-MEG3 gene region on chromosome 14q32.2 alters susceptibility to type 1 diabetes. Nat Genet. 2010;42:68-71.

55. Dehghan A, Dupuis J, Barbalic M, Bis JC, Eiriksdottir G, Lu C, et al. Metaanalysis of genome-wide association studies in $>80000$ subjects identifies multiple loci for C-reactive protein levels. Circulation. 2011;123:731-8.

56. Roederer M, Quaye L, Mangino M, Beddall MH, Mahnke Y, Chattopadhyay P, et al. The genetic architecture of the human immune system: a bioresource for autoimmunity and disease pathogenesis. Cell. 2015;161:387-403.

57. Michailidou K, Beesley J, Lindstrom S, Canisius S, Dennis J, Lush MJ, et al. Genome-wide association analysis of more than 120,000 individuals identifies 15 new susceptibility loci for breast cancer. Nat Genet. 2015;47:373-80.

58. Speedy HE, Di Bernardo MC, Sava GP, Dyer MJS, Holroyd A, Wang Y, et al. A genome-wide association study identifies multiple susceptibility loci for chronic lymphocytic leukemia. Nat Genet. 2014;46:56-60.

59. Berndt SI, Skibola CF, Joseph V, Camp NJ, Nieters A, Wang Z, et al. Genomewide association study identifies multiple risk loci for chronic lymphocytic leukemia. Nat Genet. 2013;45:868-76.

60. Law MH, Bishop DT, Lee JE, Brossard M, Martin NG, Moses EK, et al. Genome-wide meta-analysis identifies five new susceptibility loci fo cutaneous malignant melanoma. Nat Genet. 2015;47:987-95.

61. Iles MM, Law MH, Stacey SN, Han J, Fang S, Pfeiffer R, et al. A variant in FTO shows association with melanoma risk not due to BMI. Nat Genet. 2013;45: 428-32. 432e1.

62. Barrett JH, Iles MM, Harland M, Taylor JC, Aitken JF, Andresen PA, et al. Genome-wide association study identifies three new melanoma susceptibility loci. Nat Genet. 2011:43:1108-13.

63. Macgregor S, Montgomery GW, Liu JZ, Zhao ZZ, Henders AK, Stark M, et al. Genome-wide association study identifies a new melanoma susceptibility locus at 1q21.3. Nat Genet. 2011;43:1114-8.

64. Al-Tassan NA, Whiffin N, Hosking FJ, Palles C, Farrington SM, Dobbins SE, et al. A new GWAS and meta-analysis with 1000Genomes imputation identifies novel risk variants for colorectal cancer. Sci Rep. 2015;5:10442.

65. Peters U, Jiao S, Schumacher FR, Hutter CM, Aragaki AK, Baron JA, et al. Identification of genetic susceptibility loci for colorectal tumors in a genome-wide meta-analysis. Gastroenterology. 2013;144:799-807.

66. Tomlinson IPM, Carvajal-Carmona LG, Dobbins SE, Tenesa A, Jones AM, Howarth K, et al. Multiple common susceptibility variants near BMP pathway loci GREM1, BMP4, and BMP2 explain part of the missing heritability of colorectal cancer. PLoS Genet. 2011;7:e1002105.

67. Al Olama AA, Kote-Jarai Z, Berndt SI, Conti DV, Schumacher F, Han Y, et al. A meta-analysis of 87,040 individuals identifies 23 new susceptibility loci for prostate cancer. Nat Genet. 2014;46:1103-9.

68. Eeles RA, Olama AA, Benlloch S, Saunders EJ, Leongamornlert DA, Tymrakiewicz $M$, et al. Identification of 23 new prostate cancer susceptibility loci using the iCOGS custom genotyping array. Nat Genet. 2013;45:385-91.

69. Kote-Jarai Z, Olama AA, Giles GG, Severi G, Schleutker J, Weischer M, et al. Seven prostate cancer susceptibility loci identified by a multi-stage genome-wide association study. Nat Genet. 2011;43:785-91.

70. Eeles RA, Kote-Jarai Z, Al Olama AA, Giles GG, Guy M, Severi G, et al. Identification of seven new prostate cancer susceptibility loci through a genome-wide association study. Nat Genet. 2009;41:1116-21.

71. Eeles RA, Kote-Jarai Z, Giles GG, Olama AA, Guy M, Jugurnauth SK, et al. Multiple newly identified loci associated with prostate cancer susceptibility. Nat Genet. 2008:40:316-21.

72. Schumacher FR, Berndt SI, Siddiq A, Jacobs KB, Wang Z, Lindstrom S, et al. Genome-wide association study identifies new prostate cancer susceptibility loci. Hum Mol Genet. 2011;20:3867-75.

73. Gudmundsson J, Sulem P, Gudbjartsson DF, Blondal T, Gylfason A, Agnarsson BA, et al. Genome-wide association and replication studies identify four variants associated with prostate cancer susceptibility. Nat Genet. 2009;41:1122-6.

74. Gudmundsson J, Sulem P, Rafnar T, Bergthorsson JT, Manolescu A, Gudbjartsson D, et al. Common sequence variants on 2p15 and Xp11.22 confer susceptibility to prostate cancer. Nat Genet. 2008;40:281-3.
75. Gudmundsson J, Sulem P, Manolescu A, Amundadottir LT, Gudbjartsson D, Helgason A, et al. Genome-wide association study identifies a second prostate cancer susceptibility variant at 8q24. Nat Genet. 2007;39:631-7.

76. Al Olama AA, Kote-Jarai Z, Giles GG, Guy M, Morrison J, Severi G, et al. Multiple loci on 8q24 associated with prostate cancer susceptibility. Nat Genet. 2009:41:1058-60.

77. Gudmundsson J, Sulem P, Steinthorsdottir V, Bergthorsson JT, Thorleifsson G, Manolescu A, et al. Two variants on chromosome 17 confer prostate cancer risk, and the one in TCF2 protects against type 2 diabetes. Nat Genet. 2007:39:977-83.

78. Sun J, Zheng SL, Wiklund F, Isaacs SD, Purcell LD, Gao Z, et al. Evidence for two independent prostate cancer risk-associated loci in the HNF1B gene at 17q12. Nat Genet. 2008;40:1153-5.

79. Amin Al Olama A, Kote-Jarai Z, Schumacher FR, Wiklund F, Berndt SI, Benlloch S, et al. A meta-analysis of genome-wide association studies to identify prostate cancer susceptibility loci associated with aggressive and non-aggressive disease. Hum Mol Genet. 2013;22:408-15

80. Locke AE, Kahali B, Berndt SI, Justice AE, Pers TH, Day FR, et al. Genetic studies of body mass index yield new insights for obesity biology. Nature. 2015;518:197-206.

81. Shungin D, Winkler TW, Croteau-Chonka DC, Ferreira T, Locke AE, Mägi R, et al. New genetic loci link adipose and insulin biology to body fat distribution. Nature. 2015;518:187-96.

82. R Development Core Team. R: A Language and Environment for Statistical Computing. Vienna, Austria; 2010. ISBN number:3-900051-07-0.

83. Warnes G, Bolker B, Bonebakker L, Gentleman R, Huber W, Liaw A, et al. gplots: Various $\mathrm{R}$ programming tools for plotting data. The Comprehensive R Archive Network 2013. http://www.R-project.org/.

84. Neuwirth E. RColorBrewer: ColorBrewer Palettes. https://cran.r-project.org/ package $=$ RColorBrewer.

85. So H-C, Gui AHS, Cherny SS, Sham PC. Evaluating the heritability explained by known susceptibility variants: a survey of ten complex diseases. Genet Epidemiol. 2011;35:310-7.

86. Yekutieli D, Benjamini Y. The control of the false discovery rate in multiple testing under dependency. Ann Stat. 2001;29:1165-88.

87. Lee PH, O'Dushlaine C, Thomas B, Purcell SM. INRICH: interval-based enrichment analysis for genome-wide association studies. Bioinformatics. 2012;28:1797-9.

88. Flicek P, Amode MR, Barrell D, Beal K, Billis K, Brent S, et al. Ensembl 2014. Nucleic Acids Res. 2014:42:D749-55.

89. Bulik-Sullivan B, Finucane HK, Anttila V, Gusev A, Day FR, Loh P-R, et al. An atlas of genetic correlations across human diseases and traits. Nat Genet. 2015;47(11):1236-41.

90. Kao L-T, Wang K-H, Lin H-C, Tsai M-C, Chung S-D. Association between psoriasis and neovascular age-related macular degeneration: A populationbased study. J Am Acad Dermatol. 2015;72:1090-2.

91. Keenan TDL, Goldacre R, Goldacre MJ. Associations between age-related macular degeneration, osteoarthritis and rheumatoid arthritis: record linkage study. Retina. 2015;35:2613-8.

92. Nitsch D, Douglas I, Smeeth L, Fletcher A. Age-related macular degeneration and complement activation-related diseases: a population-based casecontrol study. Ophthalmology. 2008;115:1904-10.

93. Camelo S. Potential sources and roles of adaptive immunity in age-related macular degeneration: shall we rename AMD into autoimmune macular disease? Autoimmune Dis. 2014;2014:1-11.

94. Morohoshi K, Goodwin AM, Ohbayashi M, Ono SJ. Autoimmunity in retinal degeneration: autoimmune retinopathy and age-related macular degeneration. J Autoimmun. 2009;33:247-54.

95. lannaccone A, Neeli I, Krishnamurthy P, Lenchik NI, Wan H, Gerling IC, et al. Autoimmune biomarkers in age-related macular degeneration: a possible role player in disease development and progression. Adv Exp Med Biol. 2012;723:11-6.

96. Keilhauer CN, Fritsche LG, Guthoff R, Haubitz I, Weber BH. Age-related macular degeneration and coronary heart disease: Evaluation of genetic and environmental associations. Eur J Med Genet. 2013;56:72-9.

97. Nguyen-Khoa B-A, Goehring EL, Werther W, Gower EW, Do DV, Jones JK. Hospitalized cardiovascular diseases in neovascular age-related macular degeneration. Arch Ophthalmol (Chicago, III 1960). 2008;126:1280-6.

98. Wu J, Uchino M, Sastry SM, Schaumberg DA. Correction: age-related macular degeneration and the incidence of cardiovascular disease: a systematic review and meta-analysis. PLoS One. 2014;9:e89600.

99. Hyman L, Schachat AP, He Q, Leske MC. Hypertension, cardiovascular disease, and age-related macular degeneration. Age-Related Macular Degeneration Risk Factors Study Group. Arch Ophthalmol (Chicago, III 1960). 2000;118:351-8. 
100. Liao D, Mo J, Duan Y, Klein R, Scott IU, Huang KA, et al. Is age-related macular degeneration associated with stroke among elderly Americans? Open Ophthalmol J. 2008;2:37-42.

101. Duan Y, Mo J, Klein R, Scott IU, Lin H-M, Caulfield J, et al. Age-related macular degeneration is associated with incident myocardial infarction among elderly Americans. Ophthalmology. 2007;114:732-7.

102. Reitz C, Tang M-X, Schupf N, Manly JJ, Mayeux R, Luchsinger JA. Association of higher levels of high-density lipoprotein cholesterol in elderly individuals and lower risk of late-onset Alzheimer disease. Arch Neurol. 2010;67(12):1491-7.

103. McGrowder D, Riley C, Morrison EYSA, Gordon L. The role of high-density lipoproteins in reducing the risk of vascular diseases, neurogenerative disorders, and cancer. Cholesterol. 2011;2011:1-9.

104. Paun CC, Ersoy L, Schick T, Groenewoud JMM, Lechanteur YT, Fauser S, et al. Genetic variants and systemic complement activation levels are associated with serum lipoprotein levels in age-related macular degeneration. Invest Ophthalmol Vis Sci. 2015;56:7766.

105. Cougnard-Grégoire A, Delyfer M-N, Korobelnik J-F, Rougier M-B, Le Goff M, Dartigues J-F, et al. Elevated high-density lipoprotein cholesterol and agerelated macular degeneration: the Alienor study. PLoS One. 2014;9:e90973.

106. Klein R, Myers CE, Buitendijk GHS, Rochtchina E, Gao X, de Jong PTVM, et al. Lipids, lipid genes, and incident age-related macular degeneration: the three continent age-related macular degeneration consortium. Am J Ophthalmol. 2014;158:513-24.e3.

107. Parra S, Vives G, Ferré R, González M, Guardiola M, Ribalta J, et al. Complement system and small HDL particles are associated with subclinical atherosclerosis in SLE patients. Atherosclerosis. 2012;225:224-30.

108. Robman L, Baird PN, Dimitrov PN, Richardson AJ, Guymer RH. C-reactive protein levels and complement factor $\mathrm{H}$ polymorphism interaction in age-related macular degeneration and its progression. Ophthalmology. 2010;117:1982-8.

109. Klein R, Myers CE, Cruickshanks KJ, Gangnon RE, Danforth LG, Sivakumaran TA, et al. Markers of inflammation, oxidative stress, and endothelial dysfunction and the 20-year cumulative incidence of early age-related macular degeneration: the Beaver Dam Eye Study. JAMA Ophthalmol. 2014;132:446-55.

110. Cuellar-Partida G, Craig JE, Burdon KP, Wang JJ, Vote BJ, Souzeau E, et al. Assessment of polygenic effects links primary open-angle glaucoma and age-related macular degeneration. Sci Rep. 2016;6:26885.

111. Pan C-W, Cheung CY, Aung T, Cheung C-M, Zheng Y-F, Wu R-Y, et al. Differential associations of myopia with major age-related eye diseases: the Singapore Indian Eye Study. Ophthalmology. 2013;120:284-91.

112. Cheung CMG, Tai ES, Kawasaki R, Tay WT, Lee JL, Hamzah H, et al. Prevalence of and risk factors for age-related macular degeneration in a multiethnic Asian cohort. Arch Ophthalmol (Chicago, III 1960). 2012;130:480-6.

113. Lin S-C, Singh K, Chao DL, Lin SC. Refractive error and the risk of age-related macular degeneration in the South Korean population. Asia Pacific Ophthalmol (Philadelphia, Pa). 2016;5:115-21.

114. Li Y, Wang J, Zhong X, Tian Z, Wu P, Zhao W, et al. Refractive error and risk of early or late age-related macular degeneration: a systematic review and meta-analysis. PLoS One 2014:9:e90897.

115. Millen AE, Meyers KJ, Liu Z, Engelman CD, Wallace RB, LeBlanc ES, et al. Association between vitamin D status and age-related macular degeneration by genetic risk. JAMA Ophthalmol. 2015;133:1171-9.

116. Tang BMP, Eslick GD, Nowson C, Smith C, Bensoussan A. Use of calcium or calcium in combination with vitamin $\mathrm{D}$ supplementation to prevent fractures and bone loss in people aged 50 years and older: a meta-analysis. Lancet. 2007:370:657-66.

117. Titus-Ernstoff L, Perry AE, Spencer SK, Gibson JJ, Cole BF, Ernstoff MS. Pigmentary characteristics and moles in relation to melanoma risk. Int J Cancer. 2005;116:144-9.

118. Langholz B, Richardson J, Rappaport E, Waisman J, Cockburn M, Mack T. Skin characteristics and risk of superficial spreading and nodular melanoma (United States). Cancer Causes Control. 2000;11:741-50.

119. Bressler SB, Muñoz B, Solomon SD, West SK, Salisbury Eye Evaluation (SEE) Study Team. Racial differences in the prevalence of age-related macular degeneration: the Salisbury Eye Evaluation (SEE) Project. Arch Ophthalmol (Chicago, III 1960). 2008;126:241-5.

120. Williams GC. Pleiotropy, natural selection, and the evolution of senescence Sci Aging Knowl Environ. 2001;2001:cp13.

121. Tosato M, Zamboni V, Ferrini A, Cesari M. The aging process and potential interventions to extend life expectancy. Clin Interv Aging. 2007;2:401-12.

\section{Submit your next manuscript to BioMed Central and we will help you at every step:}

- We accept pre-submission inquiries

- Our selector tool helps you to find the most relevant journal

- We provide round the clock customer support

- Convenient online submission

- Thorough peer review

- Inclusion in PubMed and all major indexing services

- Maximum visibility for your research

Submit your manuscript at www.biomedcentral.com/submit

) Biomed Central 